\title{
Efeito da Adição de Propileno aos Gases de Proteção Convencionais na Soldagem GMAW Aplicada a Juntas de Topo e Ângulo
}

Guilherme Maranhão Costa ${ }^{1}$, Elaine Cristina Pereira² ${ }^{2}$ Ronaldo Pinheiro da Rocha Paranhos ${ }^{2}$ (1)

${ }^{1}$ Universidade Estadual do Norte Fluminense - UENF, Programa de Pós-graduação em Engenharia e Ciência dos Materiais - PPGECM, Campos dos Goytacazes, RJ, Brasil.

2 Universidade Estadual do Norte Fluminense - UENF, Centro de Ciência e Tecnologia - CCT, Laboratório de Materiais Avançados - LAMAV, Campos dos Goytacazes, RJ, Brasil.

Como citar: Costa GM, Pereira EC, Paranhos RPR. Efeito da adição de propileno aos gases de proteção convencionais na soldagem GMAW aplicada a juntas de topo e ângulo. Soldagem \& Inspeção. 2019;24:e2426. https://doi.org/10.1590/0104-9224/SI24.26

\begin{abstract}
Resumo: O presente trabalho teve por objetivo avaliar a adição de 1,3\% de $\mathrm{C}_{3} \mathrm{H}_{6}$ ao $\mathrm{CO}_{2}$ puro e $0,6 \%$ de $\mathrm{C}_{3} \mathrm{H}_{6}$ à mistura de $\mathrm{Ar}+25 \% \mathrm{CO}_{2}$, na soldagem de aço carbono utilizando o processo Gas Metal Arc Welding (GMAW) aplicado em juntas de topo com chanfro em V e ângulo em T. As soldas foram realizadas utilizando chapas de aço SAE 1020, arame de solda ER70S-6 de 1,2 mm, distância bico de contato à peça (DBCP) de $12 \mathrm{~mm}$, velocidade de soldagem de $300 \mathrm{~mm} / \mathrm{min}$ e vazão do gás de proteção de $15 \mathrm{l} / \mathrm{min}$. As velocidades de alimentação de arame (Valim) utilizadas foram de $4 \mathrm{~m} / \mathrm{min}$ e $5 \mathrm{~m} / \mathrm{min}$ com a tensão regulada na fonte definida com base nos sinais elétricos gerados. A análise qualitativa não apontou alterações dos cordões de solda causadas pela adição de $\mathrm{C}_{3} \mathrm{H}_{6}$. A avaliação dos sinais elétricos mostrou que a adição de $\mathrm{C}_{3} \mathrm{H}_{6}$ afetou a estabilidade do processo apenas para o $\mathrm{Ar}+25 \% \mathrm{CO}_{2}$. Os resultados mostram que adição de $\mathrm{C}_{3} \mathrm{H}_{6}$ foi benéfica ao $\mathrm{CO}_{2}$, reduzindo a taxa de escória e de respingos, gerando um pequeno aumento na taxa de deposição, e aumentando os valores de garganta efetiva e penetração de raiz. Por outro lado, a adição de $\mathrm{C}_{3} \mathrm{H}_{6}$ ao $\mathrm{Ar}+25 \% \mathrm{CO}_{2}$ não foi vantajosa, resultando em maiores quantidades de escória e respingos, e redução da taxa de deposição e penetração de raiz. A adição de $\mathrm{C}_{3} \mathrm{H}_{6}$ se mostrou mais efetiva na $\mathrm{V}_{\text {alim }}$ de $5 \mathrm{~m} / \mathrm{min}$, proporcionando uma melhora do comportamento operacional do processo para $0 \mathrm{CO}_{2}$, e uma redução nos valores dos índices de estabilidade para o $\mathrm{Ar}+25 \% \mathrm{CO}_{2}$. A adição de $\mathrm{C}_{3} \mathrm{H}_{6}$ não resultou em alterações tanto da microestrutura da zona fundida (ZF) quanto nos valores de dureza. Foi possível concluir que a adição de $\mathrm{C}_{3} \mathrm{H}_{6}$ foi benéfica para o $\mathrm{CO}_{2}$, resultando em uma melhoria da estabilidade do processo e aumento da produtividade de forma geral, mas não apresentou vantagens para o $\mathrm{Ar}+25 \% \mathrm{CO}_{2}$, reduzindo a eficiência e a estabilidade do processo.
\end{abstract}

Palavras-chave: GMAW; Índices de estabilidade; Gases de proteção; Efeito do propileno; Comportamento operacional.

\section{Effect of Propylene Addition to Conventional Shielding Gases on GMAW Applied to Top and Angle Joints}

\begin{abstract}
The objective of this work was to evaluate the addition of $1.3 \% \mathrm{C}_{3} \mathrm{H}_{6}$ to pure $\mathrm{CO}_{2}$ and $0.6 \% \mathrm{C}_{3} \mathrm{H}_{6}$ to the mixture of $\mathrm{Ar}+25 \% \mathrm{CO}_{2}$ in the welding of carbon steel using the Gas Metal Arc Welding (GMAW) applied to V-groove and T-angle joints. The welds were made using SAE 1020 steel sheets, ER70S- 6 weld wire of $1.2 \mathrm{~mm}$, contact tube to workpiece distance (CTWD) of $12 \mathrm{~mm}$, welding speed of $300 \mathrm{~mm} / \mathrm{min}$ and shielding gas flow of $15 \mathrm{l} / \mathrm{min}$. The wire feed speed $\left(V_{\text {alim }}\right)$ used were $4 \mathrm{~m} / \mathrm{min}$ and $5 \mathrm{~m} / \mathrm{min}$ with the voltage defined based on the electrical signals generated. The qualitative analysis did not indicate alterations of the weld beads caused by the addition of $\mathrm{C}_{3} \mathrm{H}_{6}$. The evaluation of the electrical signals showed that the addition of $\mathrm{C}_{3} \mathrm{H}_{6}$ affected the stability of the process only for $\mathrm{Ar}+25 \% \mathrm{CO}_{2}$. The results show that addition of $\mathrm{C}_{3} \mathrm{H}_{6}$ was beneficial to $\mathrm{CO}_{2}$, reducing the slag and spatter rate, generating a small increase in deposition rate, and increasing the values of effective throat and root penetration. On the other hand, the addition of $\mathrm{C}_{3} \mathrm{H}_{6}$ to $\mathrm{Ar}+25 \% \mathrm{CO}_{2}$ was not advantageous, resulting in higher amounts of slag and spatter, and reduction of deposition rate and root penetration. The addition of $\mathrm{C}_{3} \mathrm{H}_{6}$ was more effective at $\mathrm{V}_{\text {alim }}$ of $5 \mathrm{~m} / \mathrm{min}$, providing an improvement in the process operational behavior for $\mathrm{CO}_{2}$, and a reduction in the stability index values for $\mathrm{Ar}+25 \% \mathrm{CO}_{2}$. The addition of $\mathrm{C}_{3} \mathrm{H}_{6}$ did not result in changes in both the fusion zone (ZF) microstructure and hardness values. It was possible to conclude that the addition of $\mathrm{C}_{3} \mathrm{H}_{6}$ was beneficial for $\mathrm{CO}_{2}$, resulting in improved process stability and higher productivity, but did not present advantages for $\mathrm{Ar}+25 \% \mathrm{CO}_{2}$, reducing the efficiency and stability of the process.
\end{abstract}

Key-words: GMAW; Stability of process; Shielding gases; Propylene effect; Operational behavior.

Recebido: 28 Jun., 2019. Aceito: em 03 Out., 2019

E-mails: guilherme.maranhao.costa@gmail.com (GMC), elainecp@pq.uenf.br (ECP), paranhos@uenf.br (RPRP)

Este é um artigo publicado em acesso aberto (Open Access) sob a licença Creative Commons Attribution Non-Commercial, que permite uso, distribuição e reprodução em qualquer meio, sem restrições desde que sem fins comerciais e que o trabalho original seja corretamente citado. 


\section{Introdução}

O avanço tecnológico da indústria, estimulado pelo acelerado crescimento econômico, vem impulsionando o desenvolvimento de pesquisas relacionadas aos métodos de fabricação atualmente utilizados. Neste cenário, a soldagem apresenta papel de destaque, com a busca pela melhoria de suas propriedades, como resistência mecânica e tenacidade, assim como uma melhor relação entre custo, produtividade e qualidade [1].

Tatagiba et al [2]. mostra que durante as últimas décadas tem-se observado a partir do registro de patentes um grande avanço tecnológico com relação aos equipamentos utilizados no processo Gas Metal Arc Welding (GMAW). No entanto os estudos referentes a gases de proteção, apesar de numerosos, tem foco em gases convencionais já utilizados a décadas pela indústria. Este cenário mostra que ainda existe espaço para inovação no campo de pesquisa quando se fala em gases de proteção, principalmente em relação à adição de novos componentes.

A atmosfera protetora formada por esses gases afeta parâmetros importantes da soldagem, como o tipo transferência metálica, a estabilidade do arco elétrico, a quantidade de escória e respingos gerados, as características mecânicas e metalúrgicas do metal ou liga metálica, a geometria e descontinuidades no cordão de solda. A influência do gás de proteção no processo GMAW possibilita o estudo com diferentes misturas de gases, com o objetivo de suprir determinadas necessidades da indústria que as misturas de gases convencionais não satisfazem [3].

A estabilidade do processo de soldagem é uma das características mais afetadas pelos gases de proteção. Segundo Scotti e Ponomarev [4] a estabilidade do processo GMAW consiste na capacidade de manter um processo repetitivo com boa aparência operacional, o que resultaria em poucos ruídos e respingos e em cordões de solda de boa aparência. Para poder avaliar o desempenho do processo GMAW, muitos autores propuseram índices que mensurassem a estabilidade do mesmo quando operando em curto-circuito, sendo os que mais utilizados: o Desvio Padrão de Picos de Corrente (DPPC), o Desvio Padrão do Período de Arco Aberto (DPAA), o Desvio Padrão do Período de Curto Circuito (DPCC), o Índice Vilarinho de Regularidade da Transferência em Curto-Circuito (IVcc). Estudos que utilizaram estes índices para medir a estabilidade do processo GMAW mostraram que conforme os valores desses índices diminuem, a estabilidade do processo aumenta, o que era observado pela redução da quantidade de respingos gerados e pelo aumento na regularidade da transferência metálica [4-6].

Nos últimos anos, alguns trabalhos vêm estudando a viabilidade da aplicação de gases combustíveis em atmosferas protetoras convencionais. Tatagiba [7] e Menezes [8] mostraram que a adição de $\mathrm{H} 2$ em misturas de proteção convencionais contendo $\mathrm{CO}_{2}$ tende a melhorar a estabilidade do processo sem alterar a microestrutura e as propriedades do metal de solda, com a diminuição da taxa de respingos, sendo este efeito mais pronunciado em gases com teor elevado de $\mathrm{CO}_{2}$.

Ribeiro [9] mostrou que a adição de até $1,5 \% \mathrm{C}_{3} \mathrm{H}_{6}$ à mistura de $\mathrm{Ar}+25 \mathrm{CO}_{2}$ e a adição de até $2,5 \% \mathrm{C}_{3} \mathrm{H}_{6}$ ao $\mathrm{CO}_{2}$, na soldagem GMAW com transferência por curto-circuito gerou soldas de qualidade adequada, com bom aspecto visual e isentas de descontinuidades. As adições de $\mathrm{C}_{3} \mathrm{H}_{6}$ resultaram em uma maior média dos picos de corrente, menor desvio padrão dos períodos de curto-circuito, melhor regularidade da transferência metálica, sem provocar alterações significativas na microestrutura, na composição química e no perfil de dureza do metal de solda.

Polonine [10] analisou os efeitos da adição de $0,6 \%$ de $\mathrm{C}_{3} \mathrm{H}_{6}$ à mistura de $\mathrm{Ar}+25 \% \mathrm{CO}_{2}$, e $1,3 \% \mathrm{C}_{3} \mathrm{H}_{6}$ ao $\mathrm{CO}_{2}$ puro em cordões sobre a chapa com o processo GMAW e transferência por curto-circuito. Os resultados mostram que a adição de $\mathrm{C}_{3} \mathrm{H}_{6}$ ao $\mathrm{CO} 2$ proporcionou um ganho significativo na estabilidade do processo, com redução da quantidade de respingos gerados e pequeno aumento da taxa de deposição. Já para o $\mathrm{Ar}+25 \% \mathrm{CO}_{2}$ a adição de propileno não proporcionou alterações significativas na estabilidade do processo nem apresentou vantagens com relação aos demais aspectos da soldagem.

$O$ presente trabalho tem como objetivo a avaliação dos efeitos da adição de $1,3 \%$ de $\mathrm{C}_{3} \mathrm{H}_{6}$ ao $\mathrm{CO}_{2}$ puro e $0,6 \%$ de $\mathrm{C}_{3} \mathrm{H}_{6}$ a mistura de $\mathrm{Ar}+25 \% \mathrm{CO}_{2}$ sobre a estabilidade do processo GMAW, utilizando juntas de topo com chanfro em $\mathrm{V}$ e ângulo em $\mathrm{T}$, visando simular uma situação operacional.

\section{Materiais e Métodos}

Para a realização das soldas foram utilizados os gases $\mathrm{Ar}+25 \% \mathrm{CO}_{2}, \mathrm{Ar}+25 \% \mathrm{CO}_{2}+0,6 \% \mathrm{C}_{3} \mathrm{H}_{6}, \mathrm{CO}_{2}$ e $\mathrm{CO}_{2}+1,3 \% \mathrm{C}_{3} \mathrm{H}_{6}$. O processo foi o GMAW com transferência metálica por curto-circuito de forma mecanizada, com chapas de aço SAE 1020 nas dimensões de $200 \times 50 \times 6,35 \mathrm{~mm}$ para as juntas em ângulo e $200 \times 50 \times 12,7 \mathrm{~mm}$ para as juntas de topo, arame de solda ER70S-6 de $1,2 \mathrm{~mm}$, distância bico de contato à peça (DBCP) de $12 \mathrm{~mm}$, velocidade de soldagem de $300 \mathrm{~mm} / \mathrm{min}$ e vazão do gás de proteção de $15 \mathrm{l} / \mathrm{min}$. As velocidades de alimentação de arame $\left(V_{\text {alim}}\right)$ foram de $4 \mathrm{~m} / \mathrm{min}$, o que gerou uma corrente entre 155 a $190 \mathrm{~A}$, e $5 \mathrm{~m} / \mathrm{min}$, gerando uma corrente entre 200 a $230 \mathrm{~A}$.

Os parâmetros foram determinados em uma das etapas de uma dissertação de mestrado [11], a partir da qual este artigo foi elaborado. A partir dos parâmetros citados no parágrafo anterior, foram realizadas soldas para cada gás de proteção e valor

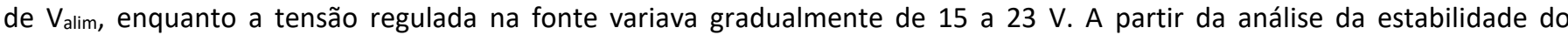
processo e do comportamento operacional apresentado pelas soldas, foram determinadas as faixas de tensão em que a estabilidade foi considerada mais adequada para a soldagem, que são mostradas na Tabela 1.

Uma matriz de experimentos foi desenvolvida contendo as faixas de tensão e os valores de tensão de trabalho a utilizados na soldagem dos corpos de prova, como mostra a Tabela 1. Foi desenvolvido um sistema de nomenclatura para a identificação dos corpos de prova, formado por quatro caracteres, onde os dois primeiros fazem referência ao gás de proteção 
utilizado ( $\mathrm{AR}-\mathrm{Ar}+25 \% \mathrm{CO} 2, \mathrm{AP}-\mathrm{Ar}+25 \% \mathrm{CO}_{2}+0,6 \% \mathrm{C}_{3} \mathrm{H}_{6}, \mathrm{CO}-\mathrm{CO}_{2}$ e $\mathrm{CP}-\mathrm{CO}_{2}+1,3 \% \mathrm{C}_{3} \mathrm{H}_{6}$ ), o terceiro indica a $\mathrm{V}_{\text {alim }}$ utilizada (4-4 $\mathrm{m} / \mathrm{min}$ e $5-5 \mathrm{~m} / \mathrm{min}$ ) e o quarto se refere ao tipo de junta (V - topo com chanfro em $\mathrm{V}, \mathrm{T}-$ ângulo em $\mathrm{T}$ ).

Tabela 1. Matriz de experimentos para a soldagem dos corpos de prova.

\begin{tabular}{|c|c|c|c|c|c|}
\hline Corpo de prova & Gás & $V_{\text {alim }}(\mathrm{m} / \mathrm{min})$ & Tipo de Junta & $\begin{array}{c}\text { Faixa operacional } \\
\text { (V) }\end{array}$ & $\begin{array}{l}\text { Tensão de trabalho } \\
\text { (V) }\end{array}$ \\
\hline AR4V & \multirow{5}{*}{$\mathrm{Ar}+25 \% \mathrm{CO}_{2}$} & 4 & V & $15-17$ & 16 \\
\hline AR5V & & 5 & V & $15-18$ & 16 \\
\hline AR4T & & 4 & $\mathrm{~T}$ & $15-17$ & 16 \\
\hline AR5T & & 5 & $\mathrm{~T}$ & $15-18$ & 16 \\
\hline AP4V & & 4 & $\mathrm{~V}$ & $15-18$ & 16 \\
\hline AP5V & $\mathrm{Ar}+25 \% \mathrm{CO}_{2}+$ & 5 & $\mathrm{~V}$ & $17-19$ & 18 \\
\hline AP4T & $0,6 \% \mathrm{C}_{3} \mathrm{H}_{6}$ & 4 & $\mathrm{~T}$ & $15-18$ & 16 \\
\hline AP5T & & 5 & $\mathrm{~T}$ & $17-19$ & 18 \\
\hline $\mathrm{CO} 4 \mathrm{~V}$ & \multirow{5}{*}{$\mathrm{CO}_{2}$} & 4 & $\mathrm{~V}$ & $18-21$ & 20 \\
\hline CO5V & & 5 & V & $19-21$ & 20 \\
\hline CO4T & & 4 & $\mathrm{~T}$ & $18-21$ & 20 \\
\hline CO5T & & 5 & $\mathrm{~T}$ & $19-21$ & 20 \\
\hline CP4V & & 4 & v & $18-21$ & 20 \\
\hline CP5V & $\mathrm{CO}_{2}+$ & 5 & v & $19-22$ & 20 \\
\hline CP4T & \multirow{2}{*}{$1,3 \% \mathrm{C}_{3} \mathrm{H}_{6}$} & 4 & $\mathrm{~T}$ & $18-21$ & 20 \\
\hline CP5T & & 5 & $\mathrm{~T}$ & $19-22$ & 20 \\
\hline
\end{tabular}

Durante a soldagem foi realizada a aquisição dos sinais elétricos gerados pelo equipamento de soldagem por meio do sistema SAPv4, que fornece os valores instantâneos de corrente, tensão, velocidade de alimentação do arame e vazão do gás de proteção gerados durante a soldagem. Os sinais foram registrados em intervalos de 0,01 s, sendo que devido a variações que ocorrem na estabilidade do processo no início e no fim da soldagem, a captação de dados foi realizada no intervalo de 10 a 35 s de um tempo de soldagem estimado de $45 \mathrm{~s}$ por cordão. 0 tratamento estatístico dos dados obtidos foi realizado diretamente pelo sistema SAPv4.

Para analisar os efeitos da adição de $\mathrm{C}_{3} \mathrm{H}_{6}$ aos gases convencionais no processo GMAW foram realizadas as seguintes avaliações:

a) Análise qualitativa dos cordões de solda: por meio de inspeção visual (IV) de acordo com a norma PR-050 [12] e por ensaio de líquido penetrante (LP) seguindo a norma PR-001 [13]. Não foram consideradas as extremidades dos cordões de solda.

b) Análise dos sinais elétricos: a estabilidade do processo GMAW pode ser medida através da repetitividade de parâmetros como a tensão e a corrente. Com base nos sinais elétricos registrados pelo sistema SAPv4 foi possível calcular os índices de estabilidade para o processo GMAW. A estabilidade da transferência metálica foi analisada através da utilização dos seguintes índices:

a) Desvio padrão de picos de corrente (DPPC);

b) Desvio padrão do período de arco aberto (DPAA);

c) Desvio padrão do período de curto circuito (DPCC);

d) Índice Vilarinho de Regularidade da Transferência em Curto-Circuito (IVcc).

O IVcc é calculado conforme a Equação 1 a seguir:

$\operatorname{IVcc}=\frac{\sigma_{\mathrm{cc}}}{\mathrm{t}_{\mathrm{cc}}}+\frac{\sigma_{\mathrm{ab}}}{\mathrm{t}_{\mathrm{ab}}}$

onde: $\sigma_{c c}=$ desvio padrão da média do tempo de curto-circuito; $\sigma_{a b}=$ desvio padrão da média do tempo de arco aberto; $\mathrm{t}_{\mathrm{cc}}=$ média do tempo de curto-circuito; $\mathrm{t}_{\mathrm{ab}}=$ média do tempo de arco aberto.

Foram construídos gráficos que mostram como os índices de estabilidade variam de acordo com o gás de proteção e valor de $V_{\text {alim }}$ para os dois tipos de juntas utilizados. A estabilidade do processo aumenta conforme os valores dos índices diminuem, ou seja, os parâmetros mais adequados para a soldagem serão aqueles que apresentarem os menores valores para os índices de estabilidade.

c) Taxa de respingos e de escória: apesar da soldagem GMAW ser um processo com proteção gasosa, a literatura [4] comenta sobre a formação de pequenas ilhas de escória sobre o cordão. Via de regra, maior o teor de $\mathrm{CO}_{2}$ na mistura gasosa, maior a quantidade de ilhas de escória formada. Os respingos e a escória gerados durante a soldagem foram 
coletados, separados com a utilização de um imã e pesados em balança com resolução de 0,001 g. A seguir foram calculadas a taxa de respingos ( $T_{\text {res, }}$ conforme a Equação 2) e a taxa de escória ( $T_{\text {esc, }}$ conforme a Equação 3 ) para cada um dos gases de proteção utilizados.

$\mathrm{T}_{\text {res }}=\frac{\mathrm{Q}_{\mathrm{res}(\mathrm{g})}}{\sum \mathrm{TS}(\mathrm{s})}$

$\mathrm{T}_{\mathrm{esc}}=\frac{\mathrm{Q}_{\mathrm{esc}}(\mathrm{g})}{\sum \mathrm{TS}(\mathrm{s})}$

onde: Qres = Quantidade de respingo; Qesc = Quantidade de escória; TS = tempo de soldagem .

d) Taxa de deposição: as chapas de teste foram pesadas antes e após a soldagem, utilizando uma balança de resolução de $0,1 \mathrm{~g}$. A partir destes valores foi possível determinar a quantidade de metal depositado pela diferença dos pesos dos corpos de prova antes e após a soldagem. A taxa de deposição foi calculada conforme a Equação 4.

Taxa de deposição $\left(\frac{\mathrm{kg}}{\mathrm{h}}\right)=\frac{\text { massa do cordão de solda }}{\text { tempo soldando a peça }}$

e) Análise geométrica: a partir das macrografias das seções transversais dos cordões de solda, realizadas com a utilização de lixas de granulometria de 100 a 600 mesh e ataque químico com solução de Nital 5\%, foram medidas, para os corpos de prova com junta de topo com chanfro em $V$ as dimensões de reforço, largura e penetração de raiz, e para os corpos de prova com junta de ângulo em $\mathrm{T}$ foram medidos os valores de perna vertical, perna horizontal e garganta efetiva. Os resultados foram comparados para avaliar possíveis alterações na geometria das juntas causadas pela adição de $\mathrm{C}_{3} \mathrm{H}_{6}$.

f) Análise Microestrutural: foi realizada através da preparação metalográfica da seção transversal de cada uma das soldas, utilizando lixas de granulometria de 100 a 1200 mesh, polimento com pasta abrasiva de alumina de $1 \mu \mathrm{m}$, e ataque com solução de Nital $2 \%$ para revelar as microestruturas da zona fundida.

g) Dureza Vickers: o ensaio de dureza foi realizado ao longo das três regiões da junta, metal base (MB), zona termicamente afetada (ZTA) e zona fundida (ZF), sendo realizadas seis medições em cada região, utilizando uma amostra para cada gás de proteção, com o durômetro calibrado para uma carga de $1 \mathrm{~kg}$ e uma impressão com duração de $10 \mathrm{~s}$.

\section{Resultados e Discussão}

a) Análise qualitativa: a Figura 1 mostra as imagens relativas aos ensaios de IV e LP respectivamente para cada um dos corpos de prova.

Os cordões de solda produzidos apresentaram um bom comportamento operacional, com uma geração de respingos e escória relativamente baixa, e uma produção de ruídos uniforme, o que já era esperado, devido ao fato dos parâmetros utilizados serem aqueles que apresentaram a estabilidade mais adequada [8]. Foi observado que as soldas produzidas com $\mathrm{Ar}+25 \% \mathrm{CO}_{2}$ (Figura 1a-d) e $\mathrm{Ar}+25 \% \mathrm{CO}_{2}+0,6 \% \mathrm{C}_{3} \mathrm{H}_{6}$ (Figura 1e-h) apresentaram menores quantidades de escória e respingos gerados se comparadas as soldas realizadas com $\mathrm{CO}_{2}$ (Figura $1 \mathrm{i}-\mathrm{I}$ ) e $\mathrm{CO}_{2}+1,3 \% \mathrm{C}_{3} \mathrm{H}_{6}$ (Figura $1 \mathrm{~m}-\mathrm{p}$ ). Também foi constatado que a adição de $\mathrm{C}_{3} \mathrm{H}_{6}$ ao $\mathrm{Ar}+25 \% \mathrm{CO}_{2}$ e $\mathrm{CO}_{2}$ não produziu alterações significativas com relação à aparência e formato do cordão de solda.

As descontinuidades no início e fim dos cordões não foram consideradas. A descontinuidade observada ao longo do cordão de solda AR5V (Figura 1b) foi atribuída ao desalinhamento entre a tocha e o chanfro, e a descontinuidade na extremidade do cordão de solda AP4T (Figura $1 \mathrm{~g}$ ) foi atribuída a um pequeno desalinhamento entre as chapas que formam as juntas. 


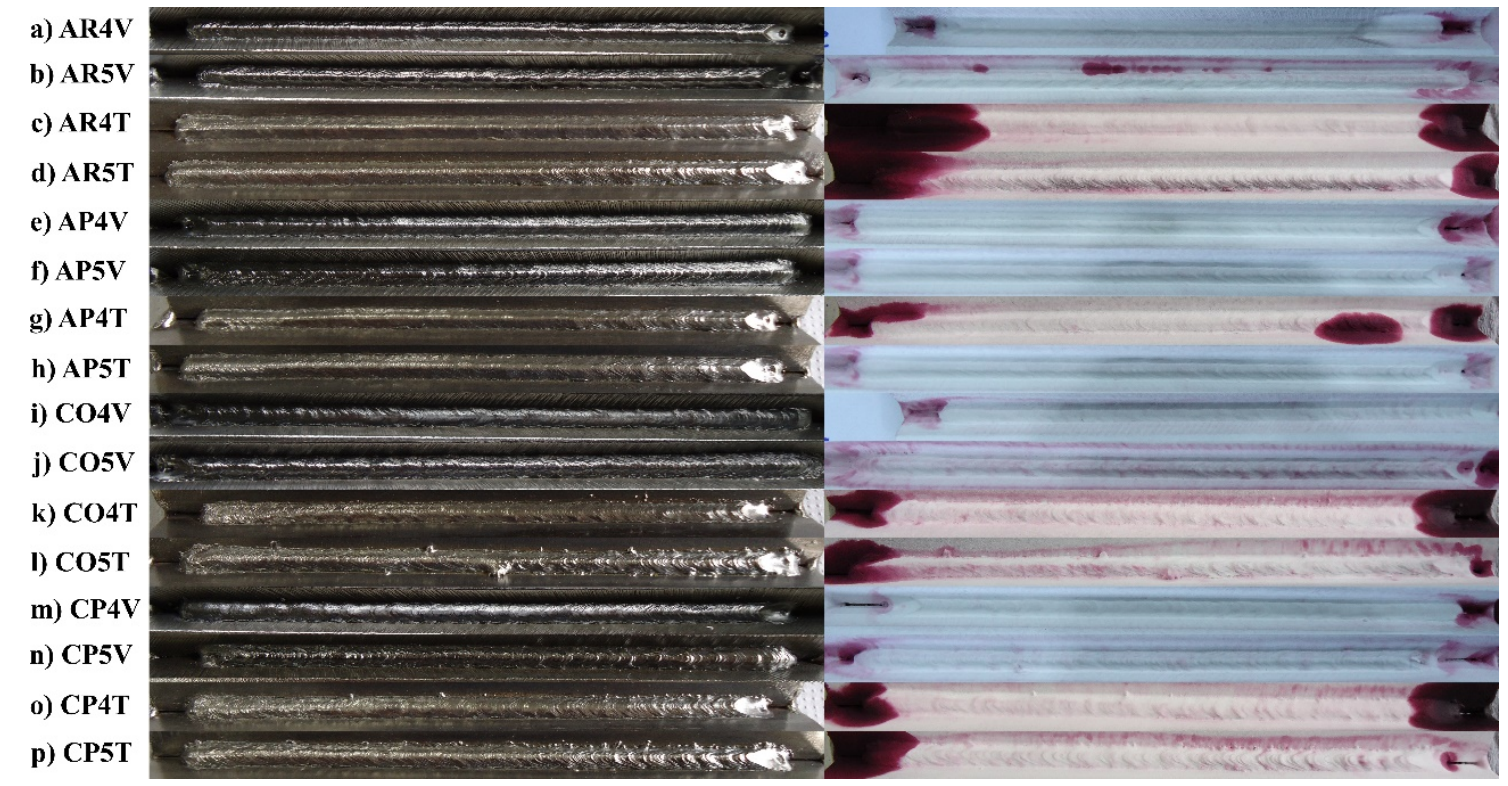

Figura 1. Ensaios de Inspeção Visual (esquerda) e Liquido Penetrante (direita).

b) Análise dos sinais elétricos:

$\mathrm{Ar}+\mathbf{2 5} \% \mathrm{CO}_{2}$ e $\mathrm{Ar}+\mathbf{2 5} \% \mathrm{CO}_{2}+\mathbf{0}, 6 \% \mathrm{C}_{3} \mathrm{H}_{6}$ : A Figura 2 mostra os índices de estabilidade dos corpos de prova que utilizaram $\mathrm{Ar}+25 \% \mathrm{CO}_{2}$ e $\mathrm{Ar}+25 \% \mathrm{CO}_{2}+0,6 \% \mathrm{C}_{3} \mathrm{H}_{6}$. Para a mistura $\mathrm{Ar}+25 \% \mathrm{CO}_{2}$, ao se comparar os resultados entre as soldas realizadas com $V_{\text {alim }}$ de $4 \mathrm{~m} / \mathrm{min}$ (AR4V e AR4T) e de $5 \mathrm{~m} / \mathrm{min}$ (AR5V e AR5T) é possível perceber que o aumento da $V_{\text {alim }}$ resulta em maiores valores para os índices de estabilidade.

Para a mistura $\mathrm{Ar}+25 \% \mathrm{CO}_{2}+0,6 \% \mathrm{C}_{3} \mathrm{H}_{6}$, o aumento da Valim de $4 \mathrm{~m} / \mathrm{min}$ (AP4V, AP4T) para $5 \mathrm{~m} / \mathrm{min}$ (AP5V, AP5T) não altera de forma significativa os valores dos índices de estabilidade, que se mantêm relativamente próximos, o que foi atribuído à adição de $\mathrm{C}_{3} \mathrm{H}_{6}$. Nesse caso, a estabilidade para as soldas realizadas com $\mathrm{Ar}+25 \% \mathrm{CO}_{2}+0,6 \% \mathrm{C}_{3} \mathrm{H}_{6}$ se encontra em um valor de tensão mais elevado.

A adição de $\mathrm{C}_{3} \mathrm{H}_{6}$, na $\mathrm{V}_{\text {alim }}$ de $4 \mathrm{~m} / \mathrm{min}$ não melhorou a estabilidade do processo, sendo que as soldas que utilizaram $\mathrm{Ar}+25 \% \mathrm{CO}_{2}+0,6 \% \mathrm{C}_{3} \mathrm{H}_{6}$ e juntas em ângulo apresentaram um ligeiro aumento dos valores dos índices de estabilidade. Já na $\mathrm{V}_{\text {alim }}$ de $5 \mathrm{~m} / \mathrm{min}$, foi observado que a adição de $\mathrm{C}_{3} \mathrm{H}_{6}$ resultou em uma significativa redução dos valores dos índices de estabilidade.

De maneira geral, a adição de $\mathrm{C}_{3} \mathrm{H}_{6}$ ao $\mathrm{Ar}+25 \% \mathrm{CO}_{2}$ se mostrou mais benéfica para maiores valores de $\mathrm{V}_{\text {alim, }}$ como a de $5 \mathrm{~m} / \mathrm{min}$, onde pode-se perceber a ocorrência de uma melhor estabilidade. Para menores valores de $V_{\text {alim, }}$ como o caso de $4 \mathrm{~m} / \mathrm{min}$, a adição de $\mathrm{C}_{3} \mathrm{H}_{6}$ ou não provoca alterações significativas ou gera uma tendência em diminuir a estabilidade do processo. Ribeiro [9] relatou que a adição de $\mathrm{C}_{3} \mathrm{H}_{6}$ ao $\mathrm{Ar}+25 \% \mathrm{CO}_{2}$ exibia pouca influência sobre a estabilidade do processo, sem provocar alterações significativas. Já Polonine [10] observou que a adição de $\mathrm{C}_{3} \mathrm{H}_{6}$ ao $\mathrm{Ar}+25 \% \mathrm{CO}_{2}$ resultou em pequena elevação dos valores dos índices de estabilidade. Os resultados obtidos por ambos os autores diferem daqueles apresentados neste trabalho. No entanto, vale ressaltar que tanto Ribeiro quanto Polonine realizaram soldas do tipo cordão sobre a chapa. Além de utilizar parâmetros ligeiramente diferentes dos aplicados neste trabalho, com uma tensão de $23 \mathrm{~V}$ utilizada por Ribeiro, e $19 \mathrm{~V}$ por Polonine. 

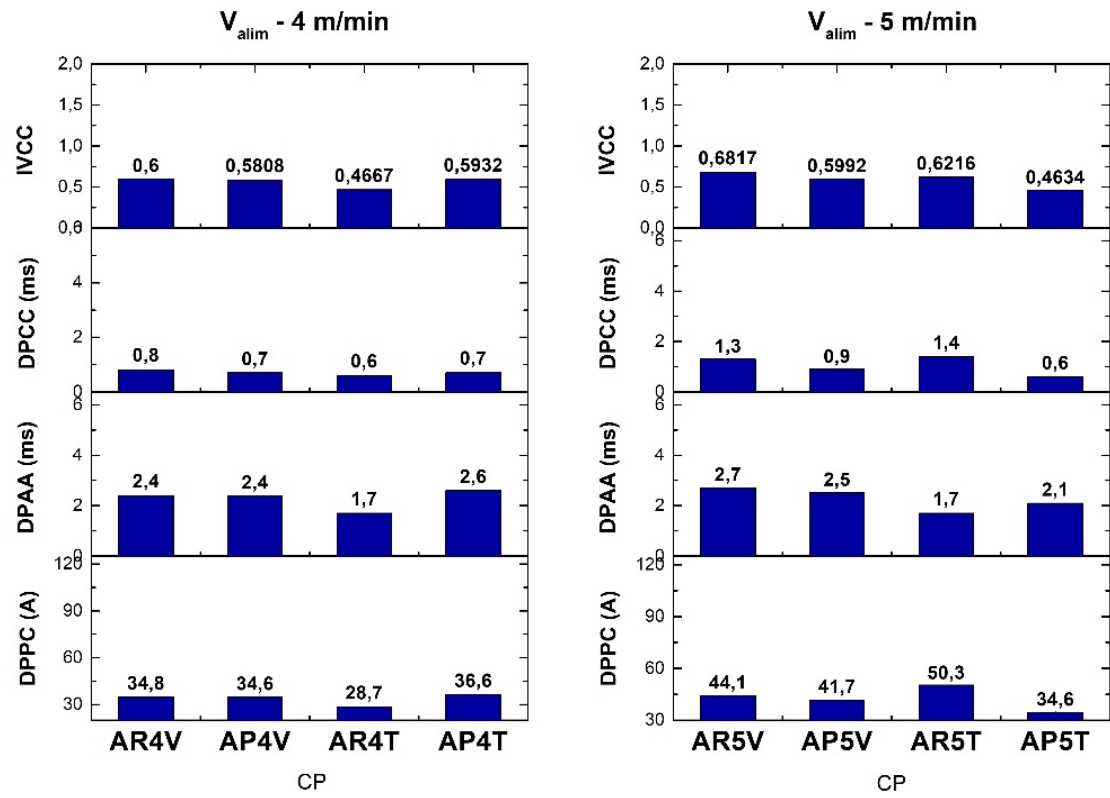

Figura 2. Índices de estabilidade das soldas realizadas com $\mathrm{Ar}+25 \% \mathrm{CO}_{2}$ e $\mathrm{Ar}+25 \% \mathrm{CO}_{2}+0,6 \% \mathrm{C}_{3} \mathrm{H}_{6}$ com $\mathrm{V}_{\text {alim }}$ de $4 \mathrm{~m} / \mathrm{min}$ (esquerda) e $\mathrm{V}_{\text {alim }}$ de $5 \mathrm{~m} / \mathrm{min}$ (direita).

$\mathrm{CO}_{2}$ e $\mathrm{CO}_{2}+1,3 \% \mathrm{C}_{3} \mathrm{H}_{6}$ : A Figura 3 mostra os índices de estabilidade calculados para os corpos de prova que utilizaram $\mathrm{CO}_{2}$ e $\mathrm{CO}_{2}+1,3 \% \mathrm{C}_{3} \mathrm{H}_{6}$. A adição de $\mathrm{C}_{3} \mathrm{H}_{6}$ não resultou em alterações significativas dos índices de estabilidade do $\mathrm{CO}_{2}$, ou seja, a estabilidade apresentada pelo processo não foi afetada sob o ponto de vista dos sinais elétricos.
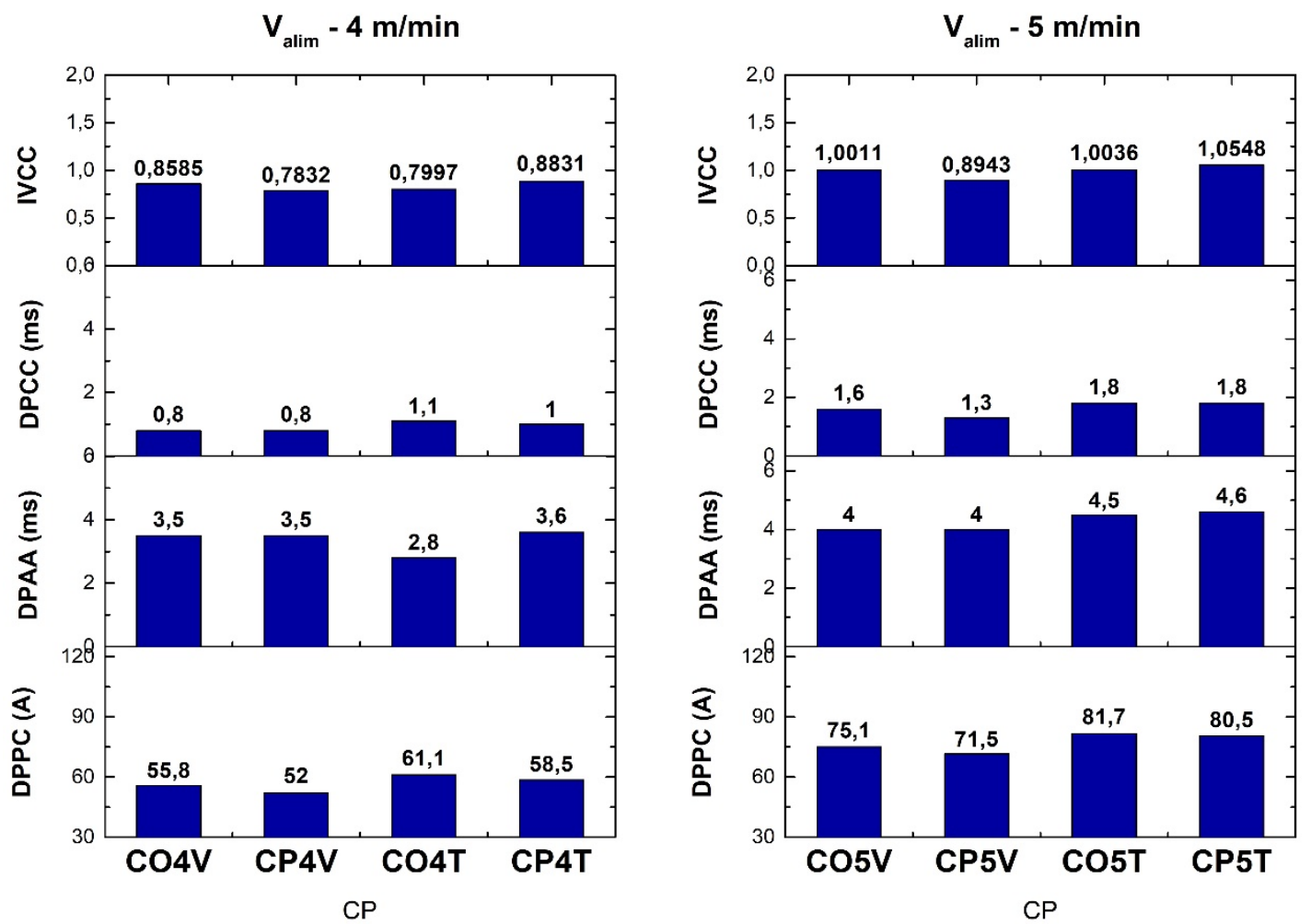

Figura 3. Índices de estabilidade das soldas realizadas com $\mathrm{CO}_{2}$ e $\mathrm{CO}_{2}+1,3 \% \mathrm{C}_{3} \mathrm{H}_{6}$ com $\mathrm{V}_{\text {alim }}$ de $4 \mathrm{~m} / \mathrm{min}$ (esquerda) e $\mathrm{V}_{\text {alim }}$ de $5 \mathrm{~m} / \mathrm{min}$ (direita). 
Não houve diferenças significativas na estabilidade entre os dois tipos de juntas utilizados, que apresentaram valores relativamente próximos dos índices de estabilidade para todos os gases e valores de $V_{\text {alim }}$ utilizados. Este comportamento indica que é possível realizar soldas com juntas de topo e juntas de ângulo com uma estabilidade adequada.

Ribeiro [9] também mostrou que a adição de $\mathrm{C}_{3} \mathrm{H}_{6}$ ao $\mathrm{CO}_{2}$ não provocou alterações significativas na estabilidade do processo. Os índices de estabilidade se mantiveram próximos para todas as soldas, e a estabilidade, de forma geral, não mostrou alterações significativas. Polonine [10] relatou que a adição de $\mathrm{C}_{3} \mathrm{H}_{6}$ ao $\mathrm{CO}_{2}$ não provocou alterações significativas nos valores dos índices de estabilidade.

Avaliação geral da estabilidade: $\mathrm{O} A r+25 \% \mathrm{CO}_{2}$ se mostrou mais sensível à adição de $\mathrm{C}_{3} \mathrm{H}_{6}$, que resultou em diminuição dos valores dos índices de estabilidade na $\mathrm{V}_{\text {alim }}$ de $5 \mathrm{~m} / \mathrm{min}$. Já a adição de $\mathrm{C}_{3} \mathrm{H}_{6}$ ao $\mathrm{CO}_{2}$ não resultou em alterações significativas nos valores dos índices de estabilidade.

Os índices de estabilidade, tanto para os gases convencionais quanto para os gases com adição de $\mathrm{C}_{3} \mathrm{H}_{6}$ se mantiveram dentro da faixa operacional definida para o processo, em que a estabilidade foi considerada a mais adequada. Este é um indicativo de que é possível obter soldas com uma estabilidade adequada utilizando gases com adição de $\mathrm{C}_{3} \mathrm{H}_{6}$.

Ao se comparar os resultados obtidos para os dois valores de $\mathrm{V}_{\text {alim }}$ utilizados, é possível perceber que a adição de $\mathrm{C}_{3} \mathrm{H}_{6} \mathrm{na}$ $V_{\text {alim }}$ de $4 \mathrm{~m} / \mathrm{min}$ não foi efetiva, com a estabilidade não variando de forma significativa. Já com a $V_{\text {alim }}$ de $5 \mathrm{~m} / \mathrm{min}$, os efeitos do $\mathrm{C}_{3} \mathrm{H}_{6}$ foram mais evidentes com relação ao $\mathrm{Ar}+25 \% \mathrm{CO}_{2}$ resultando em uma redução nos valores de vários índices de estabilidade.

Não houve grandes variações nos valores dos índices de estabilidade em relação aos dois tipos de junta utilizados, tanto para o $\mathrm{CO}_{2}$ quanto para o $\mathrm{CO}_{2}+1,3 \% \mathrm{C}_{3} \mathrm{H}_{6}$.

De modo geral, os resultados acima mostram que é possível realizar soldas com qualidade e estabilidade adequadas em juntas de topo com chanfro em $\mathrm{V}$ e juntas de ângulo em $\mathrm{T}$ utilizando gases com adição de $\mathrm{C}_{3} \mathrm{H}_{6}$.

c) Taxa de escória e respingos: a Figura 4 mostra as taxas de respingo e escória calculadas para os gases de proteção utilizados.

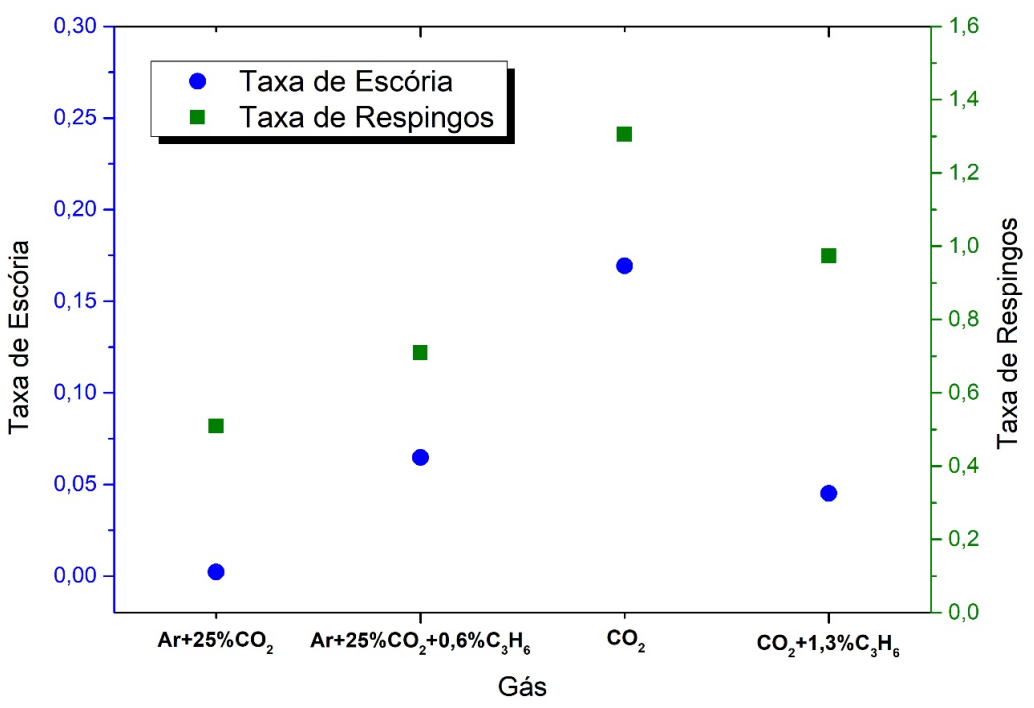

Figura 4. Taxa de respingo e taxa de escória.

$\mathrm{Ar}+\mathbf{2 5} \% \mathrm{CO}_{2}$ e $\mathrm{Ar}+\mathbf{2 5} \% \mathrm{CO}_{2}+\mathbf{0}, \mathbf{6} \% \mathrm{C}_{3} \mathrm{H}_{6}$ : A adição de $\mathrm{C}_{3} \mathrm{H}_{6}$ ao $\mathrm{Ar}+25 \% \mathrm{CO}_{2}$ resultou em um aumento na quantidade de escória e de respingos produzidos, com a taxa de escória aumentando de 0,002 $\mathrm{g} / \mathrm{min}$ para 0,06 $\mathrm{g} / \mathrm{min}$, e a taxa de respingos de $0,51 \mathrm{~g} / \mathrm{min}$ para $0,71 \mathrm{~g} / \mathrm{min}$, como mostrado na Figura 4.0 aumento da taxa de escória e de respingos foi atribuído à adição de $\mathrm{C}_{3} \mathrm{H}_{6}$, que resultou em uma redução do potencial de oxidação do $\mathrm{Ar}+25 \% \mathrm{CO}_{2}$. Como esta mistura já possui um potencial de oxidação considerado adequado para a realização da soldagem de aço carbono, um aumento ou diminuição do mesmo pode resultar em alterações da estabilidade do processo [14].

$\mathrm{CO}_{2}$ e $\mathrm{CO}_{2}+1,3 \% \mathrm{C}_{3} \mathrm{H}_{6}: A$ adição do $\mathrm{C}_{3} \mathrm{H}_{6}$ ao $\mathrm{CO}_{2}$ (Figura $5 \mathrm{~b}$ ) resultou em uma redução significativa tanto da taxa de respingos (que caiu de 1,30 para $0,97 \mathrm{~g} / \mathrm{min}$ ) quanto da taxa de escória (que caiu de 0,17 para 0,05 g/min). Esta redução foi atribuída à adição de $\mathrm{C}_{3} \mathrm{H}_{6}$, que ao se dissociar quando submetido às elevadas temperaturas do arco elétrico, se decompõe liberando $\mathrm{H}_{2}$, que atua como um gás redutor, reagindo com o $\mathrm{O}_{2}$ proveniente da dissociação do $\mathrm{CO}_{2}$, reduzindo o elevado potencial de oxidação desse gás, e consequentemente as quantidades de escória e respingos gerados [15].

Comparação entre os gases: Os resultados obtidos estão de acordo com a análise qualitativa, em que as soldas realizadas com $\mathrm{Ar}+25 \% \mathrm{CO}_{2}$ produziram a menor quantidade de escória e respingos, enquanto as soldas realizadas $\mathrm{com}^{\mathrm{CO}} \mathrm{CO}_{2}$ 
produziram a maior quantidade. Liskevych [3], que analisou a soldagem utilizando como gases de proteção Ar, misturas de Ar e $\mathrm{CO}_{2}$, e $\mathrm{CO}_{2}$ puro, constatou que a quantidade de respingos e escória gerados cresce exponencialmente com o aumento do teor de $\mathrm{CO}_{2}$ na proteção gasosa. Além disso, gases com maior concentração de $\mathrm{CO}_{2}$ também possuem uma tendência em gerar respingos de maior diâmetro, se comparados ao $\mathrm{Ar}$ e gases com baixa concentração de $\mathrm{CO}_{2}$.

Apesar da análise dos sinais elétricos não evidenciar alterações significativas em função da adição de $\mathrm{C}_{3} \mathrm{H}_{6}$ ao $\mathrm{CO}_{2}$, é possível perceber uma melhora significativa da estabilidade do processo tendo em vista a redução na taxa de escória e de respingos. Uma menor quantidade de respingos gerados resulta em menos paradas para a realização da limpeza do equipamento de soldagem devido ao acumulo de respingos na tocha. A redução dos tempos de parada implica em maior tempo efetivo de soldagem, o que resulta em maior produtividade geral do processo de soldagem. Já a adição de $\mathrm{C}_{3} \mathrm{H}_{6}$ ao $\mathrm{Ar}+25 \% \mathrm{CO}_{2}$ não se mostrou efetiva, apesar dos resultados obtidos durante a análise dos sinais elétricos indicarem uma melhoria da estabilidade na $V_{\text {alim }}$ de $5 \mathrm{~m} / \mathrm{min}$, houve um aumento da quantidade de escória e respingos gerados durante a soldagem.

A partir dos resultados acima é possível concluir que a adição de $\mathrm{C}_{3} \mathrm{H}_{6}$ foi benéfica para o $\mathrm{CO}_{2}$, pois, apesar de não alterar os valores dos índices de estabilidade calculados, resultou em uma redução significativa da taxa de escória e de respingos gerados. Por outro lado, a adição de $\mathrm{C}_{3} \mathrm{H}_{6}$ ao $\mathrm{Ar}+25 \% \mathrm{CO}_{2}$, mesmo produzindo uma redução dos valores dos índices de estabilidade na $V_{\text {alim }}$ de $5 \mathrm{~m} / \mathrm{min}$, levou a um aumento da taxa de escória e de respingos gerados durante a soldagem.

Os resultados estão de acordo com o observado por Ribeiro [9] e Polonine [10], que observaram um aumento da quantidade de escoria e respingos gerados para $\mathrm{Ar}+25 \% \mathrm{CO}_{2}$ e uma redução para o $\mathrm{CO}_{2}$ em função da adição de $\mathrm{C}_{3} \mathrm{H}_{6}$.

d) Taxa de deposição: a Figura 5 mostra os valores de taxa de deposição calculados para cada corpo de prova.
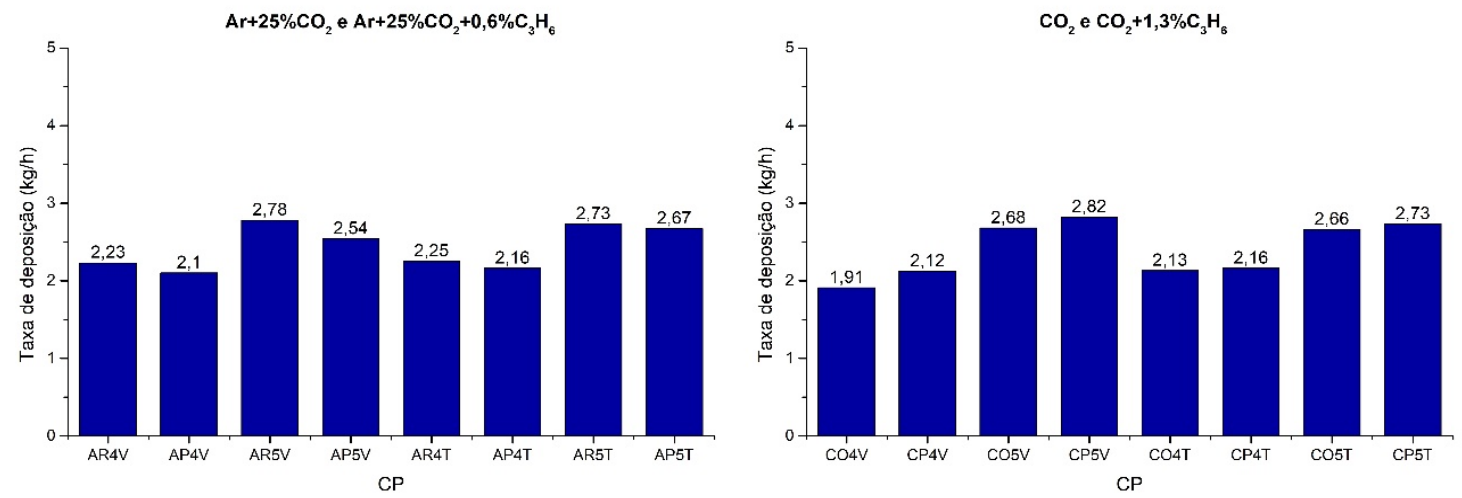

Figura 5. Taxa de deposição das soldas com $\mathrm{Ar}+25 \% \mathrm{CO}_{2}$ e $\mathrm{Ar}+25 \% \mathrm{CO}_{2}+0,6 \% \mathrm{C}_{3} \mathrm{H}_{6}$ (esquerda) e com $\mathrm{CO}_{2}$ e $\mathrm{CO}_{2}+1,3 \% \mathrm{C}_{3} \mathrm{H}_{6}$ (direita).

$\mathrm{Ar}+25 \% \mathrm{CO}_{2}$ (AR) e $\mathrm{Ar}+25 \% \mathrm{CO}_{2}+\mathbf{0}, 6 \% \mathrm{C}_{3} \mathrm{H}_{6}$ (AP): A adição de $\mathrm{C}_{3} \mathrm{H}_{6}$ ao $\mathrm{Ar}+25 \% \mathrm{CO}_{2}$ gerou uma leve tendência em diminuir os valores de TD (esquerda da Figura 5), que foi atribuída a maior quantidade de respingos e escória gerados durante a soldagem devido a adição de $\mathrm{C}_{3} \mathrm{H}_{6}$. É possível observar que a maior queda ocorreu para as juntas de topo (AP4V e AP5V), que foi atribuída ao formato da junta, que permite que a tocha fique mais próxima ao chanfro, com isso o gás de proteção atua de forma mais efetiva sobre a solda.

$\mathrm{CO}_{2}(\mathrm{CO})$ e $\mathrm{CO}_{2}+1,3 \% \mathrm{C}_{3} \mathrm{H}_{6}$ (CP): A adição de $\mathrm{C}_{3} \mathrm{H}_{6}$ ao $\mathrm{CO}_{2}$ resultou em um ligeiro aumento da TD (direita de Figura 5), que foi atribuído à redução da taxa de escória e respingos gerados durante a soldagem após a adição de $\mathrm{C}_{3} \mathrm{H}_{6}$. É possível perceber que as soldas com junta de topo com chanfro em $V$ apresentaram valores ligeiramente maiores para a TD com relação as soldas com juntas em T. Este comportamento foi atribuído à forma da junta em $V$, que permite que a tocha fique mais próxima ao chanfro, possibilitando que o gás atue de forma mais significativa sobre a poça de fusão durante a soldagem.

De modo geral, a adição de $\mathrm{C}_{3} \mathrm{H}_{6}$ foi benéfica para o $\mathrm{CO}_{2}$, que resultou em aumento da TD em ambos os valores de $V_{\text {alim }} \mathrm{e}$ tipos de junta, e não apresentou vantagens para o $\mathrm{Ar}+25 \% \mathrm{CO}_{2}$, com a TD apresentando uma pequena redução. Um incremento de TD resulta em maior quantidade de material sendo transferido para a solda, reduzindo as perdas, e resultando em maior eficiência do processo de soldagem.

Polonine [10], que utilizou $\mathrm{V}_{\text {alim }}$ de $5 \mathrm{~m} / \mathrm{min}$, obteve resultados semelhantes, com uma diminuição da TD após a adição de $\mathrm{C}_{3} \mathrm{H}_{6}$ ao $\mathrm{Ar}+25 \% \mathrm{CO}_{2}$, relacionada à maior quantidade de respingos gerados, e uma elevação da TD após a adição de $\mathrm{C}_{3} \mathrm{H}_{6}$ ao $\mathrm{CO}_{2}$, atribuída à liberação de $\mathrm{H}_{2}$ devido a decomposição do $\mathrm{C}_{3} \mathrm{H}_{6}$, que agiu como redutor controlando o potencial de oxidação do gás de proteção.

e) Análise Geométrica: a Figura 6 mostra as macrografias obtidas para as seções transversais de cada um dos corpos de prova e a Figura 7 mostra os valores obtidos durante as medições. Durante a análise não foram detectadas descontinuidades internas nos cordões de solda. Não foi possível perceber nenhum tipo de variação com relação ao formato dos cordões de solda, que apresentaram uma geometria típica de acordo com o tipo de gás e parâmetros 
utilizados sem qualquer indicio de deformidades. Também não foi possível perceber alterações significativas do formato dos cordões de solda em função da adição de $\mathrm{C}_{3} \mathrm{H}_{6}$.

A adição de $\mathrm{C}_{3} \mathrm{H}_{6}$ ao $\mathrm{Ar}+25 \% \mathrm{CO}_{2}$, resultou em uma ligeira redução da profundidade de penetração da raiz, sendo que as demais medições não apresentaram variações significativas. Este comportamento foi atribuído ao menor rendimento do processo causado após a adição de $\mathrm{C}_{3} \mathrm{H}_{6}$, que resultou em maior geração de respingos e escória e uma ligeira redução da TD.

A adição de $\mathrm{C}_{3} \mathrm{H}_{6}$ ao $\mathrm{CO}_{2}$ resultou em um leve aumento da profundidade de penetração para ambos os valores de $\mathrm{V}_{\text {alim. }}$. O que está de acordo com os resultados da análise da taxa de respingos e escória, que foram ligeiramente menores para as soldas realizadas com $\mathrm{CO}_{2}+1,3 \% \mathrm{C}_{3} \mathrm{H}_{6}$, e com o ligeiro aumento apresentado pela TD calculada.

As soldas realizadas com $\mathrm{CO}_{2}$ e $\mathrm{CO}_{2}+1,3 \% \mathrm{C}_{3} \mathrm{H}_{6}$ apresentaram menor reforço e maior largura se comparadas as soldas realizadas com $\mathrm{Ar}+25 \% \mathrm{CO}_{2}$ e $\mathrm{Ar}+25 \% \mathrm{CO}_{2}+0,6 \% \mathrm{C}_{3} \mathrm{H}_{6}$. Este comportamento já era esperado em virtude da maior tensão aplicada quando se utilizou os gases com maior concentração de $\mathrm{CO}_{2}$.

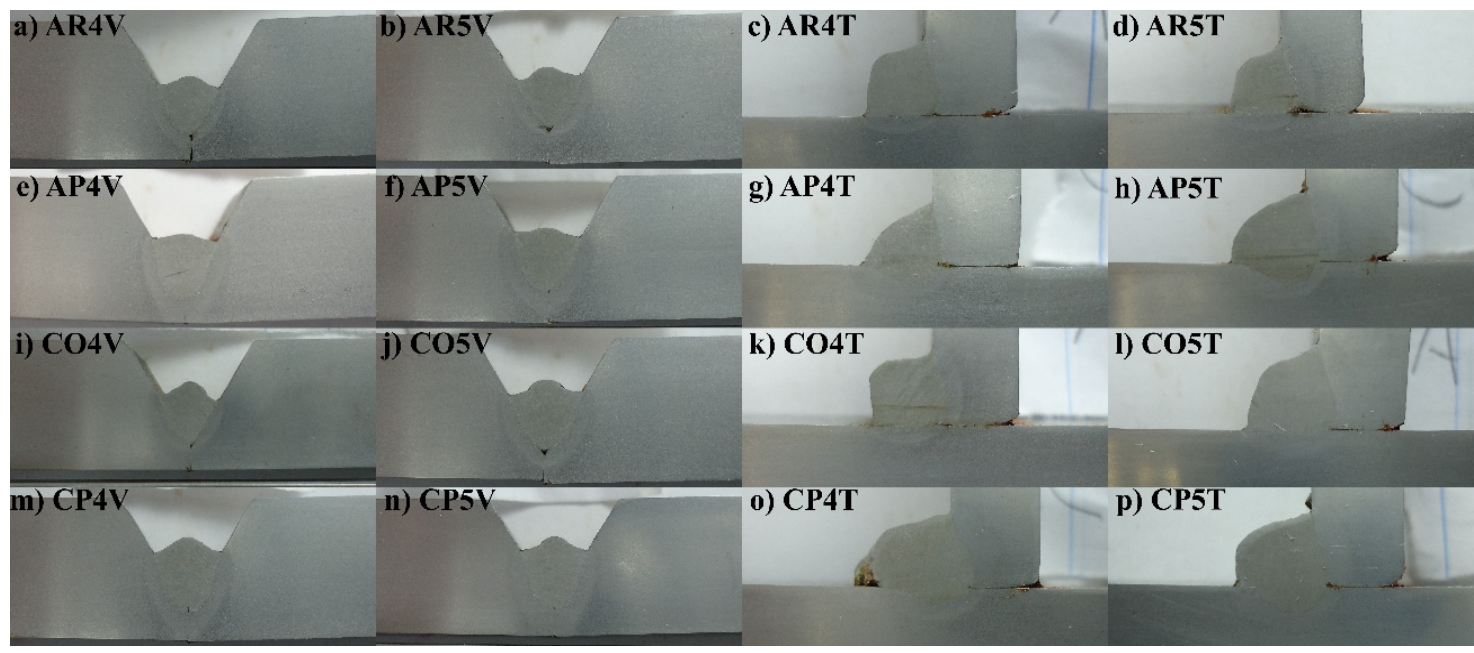

Figura 6. Macrografias dos corpos de prova.
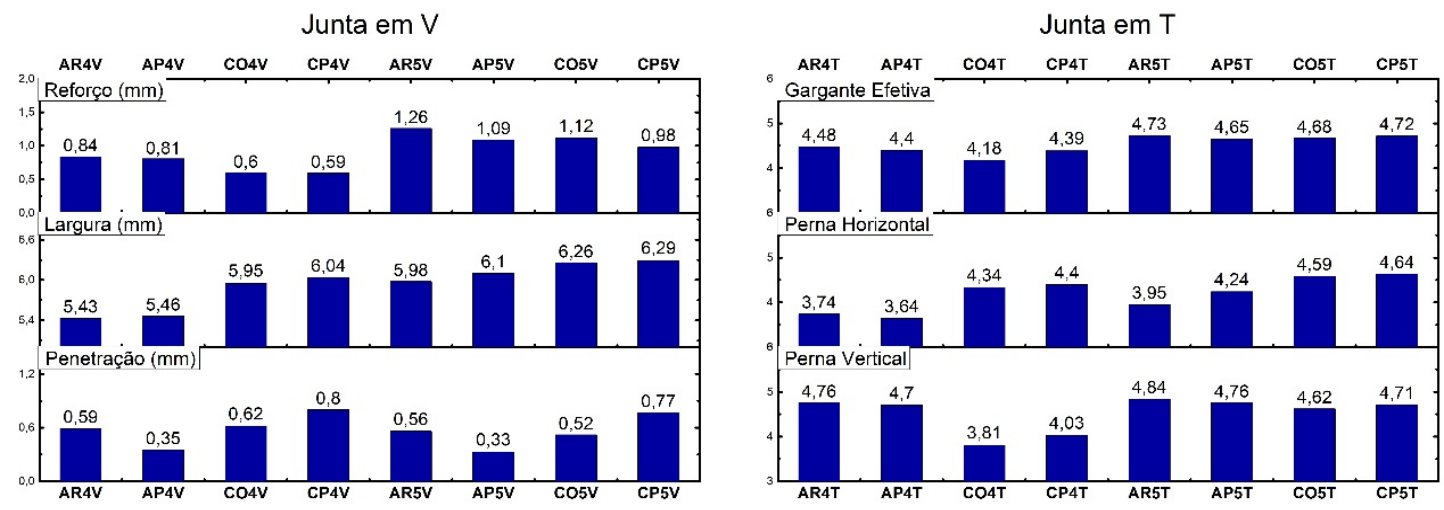

Figura 7. Dimensões dos cordões de solda com junta em V (esquerda) e junta em T (direita).

f) Análise microestrutural: as microestruturas das quatro amostras apresentaram uma predominância das fases ferrita acicular (AF), ferrita de segunda fase alinhada (FS(A)) e ferrita de contorno de grão (PF(G)), e em menor quantidade ferrita não alinhada de segunda fase (FS(NA)) e ferrita poligonal intragranular (PF(I)). Como o aço utilizado foi o SAE 1020, que possui baixo teor de carbono, a ZF não apresentou as fases martensita e agregados ferrita-carbetos. As microestruturas apresentadas estão de acordo com o descrito por Silva et al. [16], e também foram observadas por Tatagiba [7], Ribeiro [9] e Polonine [10].

Ao se comparar as microestruturas apresentadas pelas ZF, é possível perceber que as soldas que utilizaram gases com maior concentração de $\mathrm{CO}_{2}$ (Figuras $8 \mathrm{c}$ e $8 \mathrm{~d}$ ) apresentaram menor quantidade de AF. Este comportamento foi atribuído à

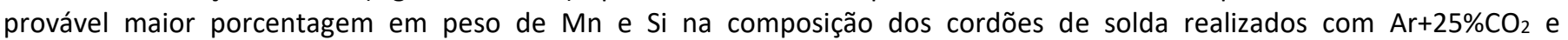
$\mathrm{Ar}+25 \% \mathrm{CO}_{2}+0,6 \% \mathrm{C}_{3} \mathrm{H}_{6}$ (Figuras $8 \mathrm{a}$ e $8 \mathrm{~b}$ ), provenientes do arame ER70S-6, que atuam como refinadores de grão, promovendo uma maior formação de AF. 
De maneira geral, não foi possível perceber alterações significativas causadas pela adição de $\mathrm{C}_{3} \mathrm{H}_{6}$ ao $\mathrm{Ar}+25 \% \mathrm{CO}_{2}$ e $\mathrm{CO}_{2}$ à microestrutura da ZF dos cordões de solda. Como pode ser visto pela Figura 8, as microestruturas apresentadas pelas soldas realizadas utilizando gases com adição de $\mathrm{C}_{3} \mathrm{H}_{6}$ foram visualmente semelhastes às apresentadas pelas soldas realizadas com gases convencionais.

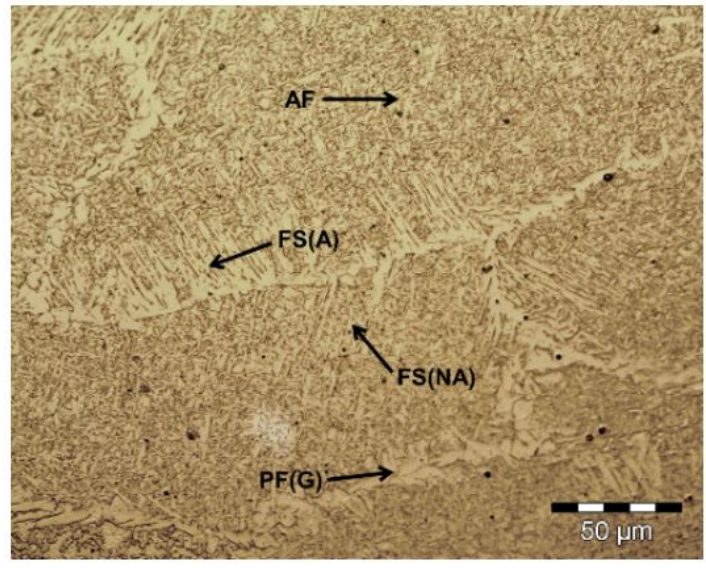

a) $\mathrm{Ar}+25 \% \mathrm{CO}_{2}$

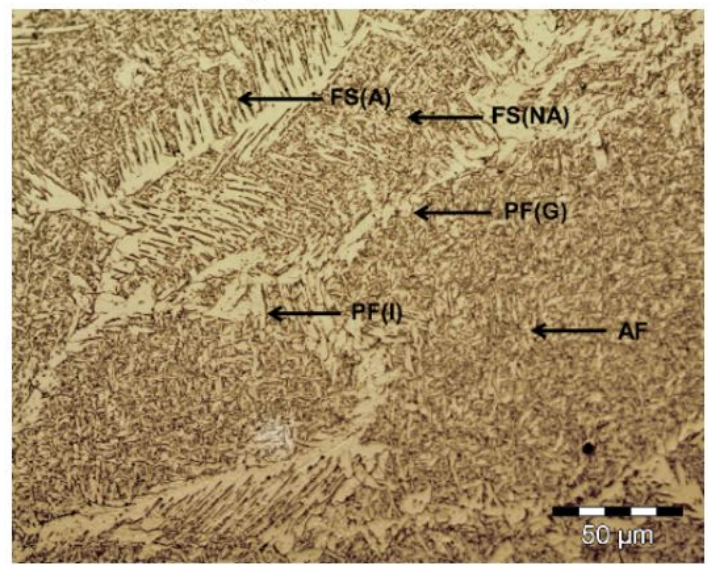

c) $\mathrm{CO}_{2}$

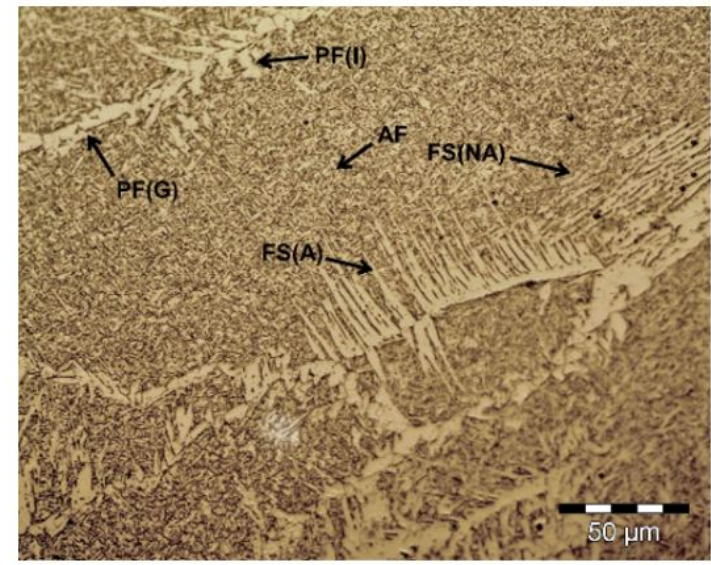

b) $\mathrm{Ar}+25 \% \mathrm{CO}_{2}+0,6 \% \mathrm{C}_{3} \mathrm{H}_{6}$

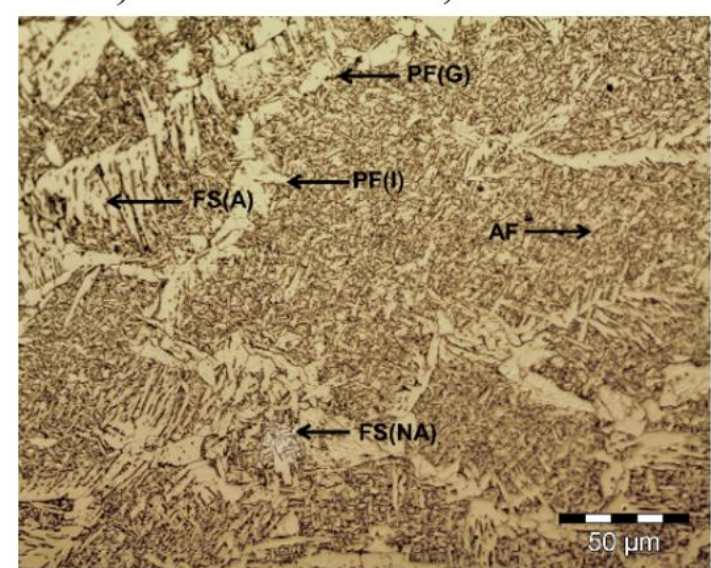

d) $\mathrm{CO}_{2}+1,3 \% \mathrm{C}_{3} \mathrm{H}_{6}$

Figura 8. Micrografias das ZF dos corpos de prova, aumento de 500x.

g) Dureza Vickers: a Tabela 2 mostra os valores médios de dureza apresentados pelas regiões que compõe o cordão de solda e a Figura 9 mostra os perfis de dureza apresentados pelas amostras analisadas.

Tabela 2. Valores médios de dureza.

\begin{tabular}{|c|c|c|c|c|}
\hline Região & $\mathrm{Ar}+25 \% \mathrm{CO}_{2}$ & $\begin{array}{l}\mathrm{Ar}+25 \% \mathrm{CO}_{2} \\
+0,6 \% \mathrm{C}_{3} \mathrm{H}_{6}\end{array}$ & $\mathrm{CO}_{2}$ & $\begin{array}{c}\mathrm{CO}_{2}+ \\
1,3 \% \mathrm{C}_{3} \mathrm{H}_{6}\end{array}$ \\
\hline$M B$ & 136,4 & 131,6 & 137,7 & 134,2 \\
\hline ZTA & 188,7 & 187,4 & 190,4 & 187,8 \\
\hline $\mathrm{ZF}$ & 242,2 & 239,2 & 227,1 & 224,3 \\
\hline
\end{tabular}




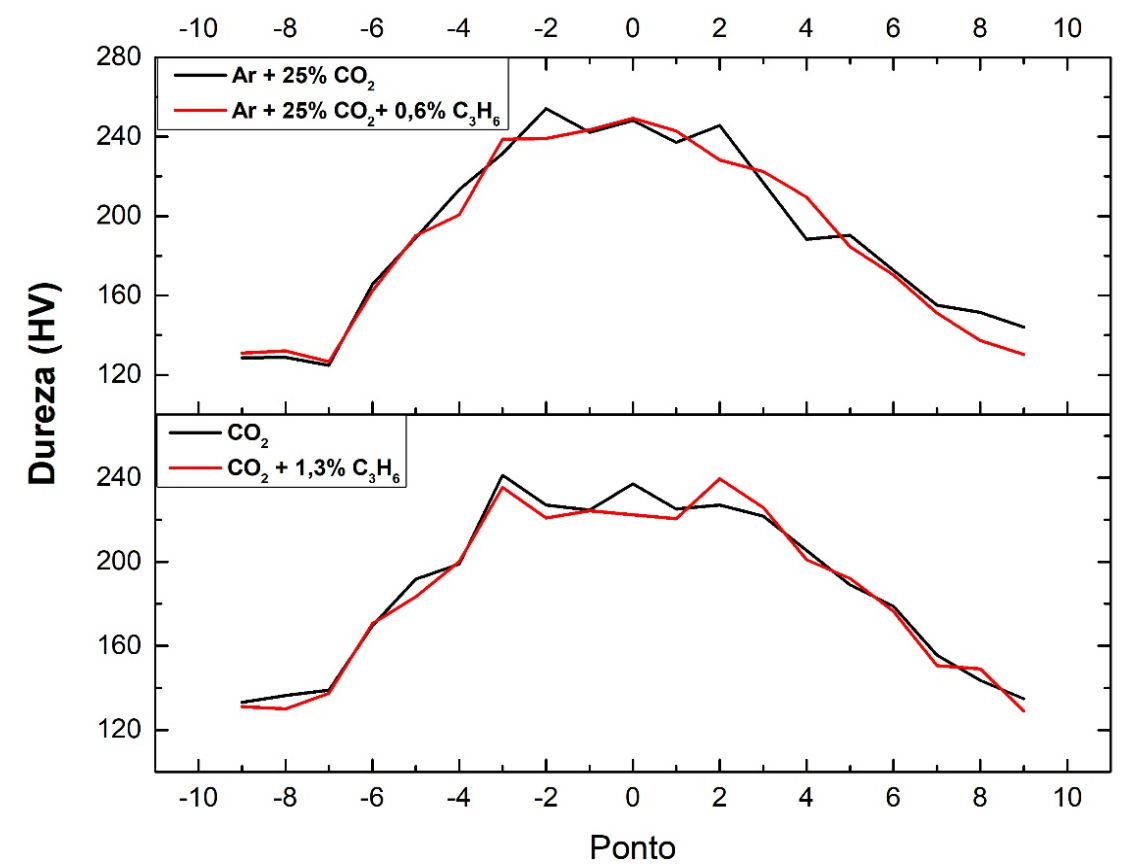

Figura 9. Perfil de dureza.

A dureza apresentada pelas amostras mostrou um comportamento típico de uma solda em aço baixo carbono, com o metal base (MB) apresentando os menores valores de dureza, a zona termicamente afetada (ZTA) apresentando valores crescentes de dureza, o que está associado as diferentes morfologias que compõe está região, e por fim a zona fundida apresentando os maiores valores de dureza, atribuídos a predominância de ferrita acicular, que se apresenta na forma de grãos pequenos e não alinhados.

Comparando os valores médios de dureza, apresentados pela Tabela 2, das soldas realizadas $\mathrm{com} \mathrm{Ar}+25 \% \mathrm{CO}_{2} \mathrm{e}$ $\mathrm{Ar}+25 \% \mathrm{CO}_{2}+0,6 \% \mathrm{C}_{3} \mathrm{H}_{6}$ em relação aquelas que utilizaram $\mathrm{CO}_{2}$ e $\mathrm{CO}_{2}+1,3 \% \mathrm{C}_{3} \mathrm{H}_{6}$, é possível perceber que, quando foram utilizados os gases com maior concentração de $\mathrm{CO}_{2}$ houve uma queda de cerca de $15 \mathrm{HV}$ nos valores médio de dureza da ZF. Este comportamento foi atribuído a diferenças nas microestruturas apresentada pela ZF, onde os gases com maior concentração de $\mathrm{CO}_{2}$ apresentaram menores quantidades de $\mathrm{AF}$, e maiores quantidades de PF e FS(A).

Após a adição de $\mathrm{C}_{3} \mathrm{H}_{6}$, não foi possível perceber alterações significativas, com as soldas realizadas com os gases com adição de $\mathrm{C}_{3} \mathrm{H}_{6}$ apresentando valores médios de dureza próximos aos apresentados pelas soldas que utilizaram gases convencionais. Esses resultados estão de acordo com a análise microestrutural, em que não foi possível notar alterações significativas na microestrutura apresentada pela $\mathrm{ZF}$ das soldas em função da adição de $\mathrm{C}_{3} \mathrm{H}_{6}$.

\section{Conclusões}

Tendo em vista o objetivo geral deste trabalho, que consiste na avaliação dos efeitos da adição de $1,3 \%$ de $\mathrm{C}_{3} \mathrm{H}_{6}$ ao $\mathrm{CO}_{2}$ puro e $0,6 \%$ de $\mathrm{C}_{3} \mathrm{H}_{6}$ a mistura de $\mathrm{Ar}+25 \% \mathrm{CO}_{2}$, na soldagem do aço carbono utilizando o processo GMAW e transferência por curto-circuito, aplicado a juntas de topo e ângulo, foi possível concluir que:

- $\quad$ A análise qualitativa mostrou que a adição de $\mathrm{C}_{3} \mathrm{H}_{6}$ aos gases convencionais não alterou o formato dos cordões de solda;

- $\quad$ A adição de $\mathrm{C}_{3} \mathrm{H}_{6}$ foi benéfica ao $\mathrm{CO}_{2}$, reduzindo as quantidades de escória e respingos, gerando um pequeno aumento na taxa de deposição, e aumentando os valores de garganta efetiva e penetração de raiz;

- $\quad$ A adição de $\mathrm{C}_{3} \mathrm{H}_{6}$ ao $\mathrm{Ar}+25 \% \mathrm{CO}_{2}$ não foi vantajosa, resultando em maiores quantidades de escória e respingos, uma taxa de deposição ligeiramente menor e menor penetração de raiz;

- Os efeitos da adição de $\mathrm{C}_{3} \mathrm{H}_{6}$ foram mais pronunciados na $\mathrm{V}_{\text {alim }}$ de $5 \mathrm{~m} / \mathrm{min}$ em comparação com a $V_{\text {alim }}$ de $4 \mathrm{~m} / \mathrm{min}$, o que mostra que valores mais elevados de $V_{\text {alim }}$ são mais efetivos para este tipo de aplicação;

- $\quad$ A adição de $\mathrm{C}_{3} \mathrm{H}_{6}$ não resultou em alterações das microestruturas e dos valores de dureza apresentados pelas regiões que compõem os cordões de solda;

- De modo geral, a adição de $\mathrm{C}_{3} \mathrm{H}_{6}$ foi benéfica para $\mathrm{o} \mathrm{CO}_{2}$, aumentando a produtividade e a estabilidade do processo de forma geral, e não apresentou vantagens para o $\mathrm{Ar}+25 \% \mathrm{CO}_{2}$, resultando em redução da eficiência do processo. 


\section{Referências}

[1] Gallego J, Ventrella VA. Inclusões na formação da ferrita acicular: caracterização por microscopia eletrônica de varredura. In: Anais do 69ำ Congresso Anual da ABM; 2014; São Paulo. São Paulo: ABCERAM; 2014. 10 p.

[2] Tatagiba LCS, Gonçalves RB, Paranhos R. Tendências no desenvolvimento de gases de proteção utilizados na soldagem GMAW. Soldagem e Inspeção. 2012;17(3):218-228. http://dx.doi.org/10.1590/S0104-92242012000300006.

[3] Liskevych O. Estudo da influência do teor de CO2 na regularidade da transferência de metal e estabilidade do processo MIG/MAG [dissertação de mestrado]. Uberlândia: Laboratório Para o Desenvolvimento de Processos de Soldagem, Universidade Federal de Uberlândia; 2010.

[4] Scotti A, Ponomarev V. Soldagem MIG/MAG: melhor entendimento, melhor desempenho. 1. ed. São Paulo: ArtLiber; 2014.

[5] Baixo CEI, Dutra JC. Influência da taxa de variação da corrente na regularidade em soldagem MIG/MAG por curto circuito. Florianópolis: Universidade Federal de Santa Catarina; 1995.

[6] Rezende GMC, Liskévych O, Vilarinho LO, Scotti A. Um critério para determinar a regulagem da tensão em soldagem MIG/MAG por curto-circuito. Soldagem e Inspeção. 2011;16(2):98-103. http://dx.doi.org/10.1590/S0104-92242011000200002.

[7] Tatagiba LCS. Formulação de gases de proteção com adições de gases redutores para a soldagem GMAW [tese de doutorado]. Campos dos Goytacazes: Universidade Estadual do Norte Fluminense Darcy Ribeiro; 2015.

[8] Menezes T. P. Estudo da adição de hidrogênio em gases de proteção convencionais na soldagem GMAW de aço de baixo carbono [dissertação de mestrado]. Campos dos Goytacazes: Universidade Estadual do Norte Fluminense Darcy Ribeiro; 2016.

[9] Ribeiro RBG. Estudo do efeito da adição de gás combustível C3H6 nas atmosferas de proteção convencionais do processo GMAW [tese de doutorado]. Campos dos Goytacazes: Universidade Estadual do Norte Fluminense Darcy Ribeiro; 2016.

[10] Polonine AF. Estudo do efeito do gás propileno no processo GMAW utilizando transferência metálica por curto-circuito [dissertação de mestrado]. Campos dos Goytacazes: Universidade Estadual do Norte Fluminense Darcy Ribeiro; 2018.

[11] Costa GM. Estudo do efeito da adição de propileno aos gases de proteção convencionais na soldagem GMAW aplicada a juntas de topo e angulo [dissertação de mestrado]. Campos dos Goytacazes: Universidade Estadual do Norte Fluminense Darcy Ribeiro; 2019.

[12] Associação Brasileira de Ensaios Não Destrutivos. PR-050: ensaio visual e dimensional de soldas. São Paulo: ABENDI; 2011.9 p. [acesso em 17 jan. 2019]. Disponível em: http://www.abendi.org.br/abendi/

[13] Associação Brasileira de Ensaios Não Destrutivos. PR-001: líquido penetrante. São Paulo: ABENDI; 2008. 8 p. . [acesso em 17 jan. 2019 ]. Disponível em: http://www.abendi.org.br/abendi/

[14] Groetelaars PJ, Scotti A. Influência do teor de $\mathrm{CO}_{2}$ no gás de proteção sobre a transferência metálica no processo MIG/MAG duploarame. Uberlândia: Laboratório Para o Desenvolvimento de Processos de Soldagem, Universidade Federal de Uberlândia; 2007. p. 2937.

[15] Suban M, Tušek J. Methods for the determination of arc stability. Journal of Materials Processing Technology. 2003;143-144:430-437. http://dx.doi.org/10.1016/S0924-0136(03)00416-3.

[16] Silva AF, Delforge DYM, Tokimatsu RC, Ventrella VA. Análise microestrutural do metal de solda de perfis soldados de um lado só utilizados na construção civil. Ilha Solteira: Faculdade de Engenharia de Ilha Solteira; 2011. p. 3-4. 